LBL -30617

DE92 017375

\title{
Low-Level Determination of Plutonium by Gamma and L X-ray Spectroscopy
}

\author{
Heino Nitsche, Raymond C. Gatti, Shan C. Lee
}

\author{
Lawrence Berkeley Laboratory \\ University of California \\ Earth Sciences Division \\ Mail Stop 70A-1150 \\ Berkeley, CA 94720 \\ U.S.A.
}

April 1991
Contribution to the American Nuclear Society (ANS) International Topical Conference on the Methods and Applications of Radioanalytical Chemistry-II,
April 21-27, 1991, Kona, Hawaii.

\begin{abstract}
Accepted for publication in the Journal of
Radioanalytical and Nuclear Chemistry.
\end{abstract}
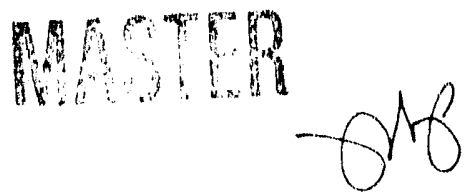

DISTRIBUTION OF THIS DOCUMENT IS UNLIMITEI.

This work was supported by the Yucca Mountain Site Characterization Project Office as part of the U.S. Civilian Radioactive Waste Management Project through the Los Alamos National Laboratory. The Y'ucca Mountain Site Characterization Project is managed by the U.S. Department of Energy, Yucca Mountain Project. This work was performed at the Lawrence Berkeley Laboratory, which is operated by the University of California for the U.S. Department of Energy under Contract DE-AC03-76SF00098. 


\begin{abstract}
We have developed an analytical method for detection of ${ }^{239} \mathrm{Pu}$ in aqueous samples at concentrations as low as $10^{-10} \mathrm{M}$. This nuclear counting technique utilizes the uranium $L \mathrm{X}$-rays, which follow the alpha decay of plutonium. Because $L X$-rays are specific for the element and not for the individual isotope, the isotopic composition of the plutonium sample must be known. The counting efficiency in the 11-23 keV range is determined from a plutonium stanclard, and the concentration of the sample is then calculated from the $L X$-ray count and the isotopic composition. The total $L X$-ray count is corrected for possible contributions from other radionuclides present as impurities by measuring the low-energy ganma spectrum for each contaminant to establish specific photon/X-ray ratios. The ratios are important when ${ }^{241} \mathrm{Pu}$ and ${ }^{242} \mathrm{Pu}$ are measured, because the respective decay chain members produce non- $\mathrm{U} L \mathrm{X}$-rays. This new method can replace the use of labor-intensive radiochemical separation techniques and elaborate activation methods for analysis of ${ }^{239} \mathrm{Pu}$ in aqueous samples. It is also applicable for assaying plutonium in liquid wastes that pose possible hazards to the environment.
\end{abstract}

\title{
INTRODUCTION
}

Solubility and speciation studies of plutonium in groundwaters and in brine solutions done in our laboratory require plutonium assays. 1,2 The solution concentrations range between $10^{-5}$ and $10^{-10} \mathrm{M}$.

The use of alpha spectroscopy for this task is limited by self-absorption effects of the dried sample and is therefore only applicable to solutions of low salt content. Addition of a yield tracer could overcome this problem, but labor-intensive separations and purifications of the sample may still be necessary. Gamma spectroscopy requires very little sample preparation and seems to be a more suitable alternative. The decay of $239 \mathrm{Pu}$ has a characteristic $\gamma$-peak at $51.62 \mathrm{keV}$. Its low abundance $(0.0208 \%)$, however, would require extremely long counting times for low concentrations and is not very suitable for the task.

Therefore, we have developed a new radioanalytical method for plutonium that utilizes the uranium $L X$-rays instead of the plutonium $\gamma$-rays. The uranium $L X$-rays come from the alpha decay of the plutonium. 


\section{CONCEPT}

$L X$-ray radiation is specific for the element and not for the individual isotope. The alpha decay of all plutonium isotopes produces uranium $L$ X-rays. Table 1 shows the overall $\mathrm{U} L \mathrm{X}$-ray intensities for the most common plutonium isotopes. Though the $U L \mathrm{X}$-ray intensity is much higher for ${ }^{238} \mathrm{Pu}$, $240 \mathrm{Pu}$, and ${ }^{242} \mathrm{Pu}$ than for ${ }^{239} \mathrm{Pu}$, the $\mathrm{U} L \mathrm{X}$-rays can be used for the analytical determination of $239 \mathrm{Pu}$. The spectrum of a plutonium sample shown in Figure 1, indicates that a much higher detection efficiency can be obtained by using the $U L \mathrm{X}$-rays instead of the $51.62 \mathrm{keV}$ photo peak of ${ }^{239} \mathrm{Pu}$. The isotopic composition and the $U L X$-ray yields of the plutonium used for our experiments are given in Table 2. Although 93.85 percent of the atoms originate from the ${ }^{239} \mathrm{pu}$ isotope, the $\mathrm{U} L \mathrm{X}$ ray intensities of ${ }^{238} \mathrm{Pu}$ and $240 \mathrm{Pu}$ are comparable to that of ${ }^{239} \mathrm{Pu}$. This emphasizes the importance of knowing the isotopic composition when using this method to analyze for plutonium.

\section{Interference from ${ }^{237} \mathrm{U}$ and ${ }^{241} \mathrm{Am}$}

The decay schemes of the plutonium isotopes (Table 3) show members of the chain that may' interfere with the plutonium determination because they also produce $L$ X-rays. Figure 1 shows the spectrum of a plutonium sample. The photon peaks at $59.54 \mathrm{keV}$ and at $208.01 \mathrm{keV}$ indicate that $237 \mathrm{U}$ and ${ }^{241} \mathrm{Am}$ are also present as a mixture. The negatron decay of $241 \mathrm{Pu}$ to ${ }^{241} \mathrm{Am}$ (Table 3, eq. 4) does not produce any Am $L$ X-rays and therefore does not interfere with the plutonium determination.

Table 1.

Nuclear properies of plutonium isotopes and overall uranium $L X$-ray intensities from their alpha-decays and for ${ }^{241} \mathrm{Pu} \beta$-decay. ${ }^{3}$

\begin{tabular}{cccc}
\hline Pu Isotope & Half-life $(y)$ & Decay mode & $\begin{array}{c}\text { U L X-ray intensity* } \\
(\text { per } 100 \alpha)\end{array}$ \\
\hline 238 & 87.74 & $\alpha$ & $10.9 \pm 0.6$ \\
239 & $2.411 \times 10^{4}$ & $\alpha$ & $4.01 \pm 0.09$ \\
240 & 6536 & $\alpha$ & $10.2 \pm 0.7$ \\
241 & 14.4 & $\beta, \alpha$ & $-4.4 \times 10^{-3}$ \\
242 & $3.76 \times 10^{5}$ & $\alpha$ & $8.6 \pm 1.2$ \\
\hline
\end{tabular}

*Calculated from data in reference 3. 


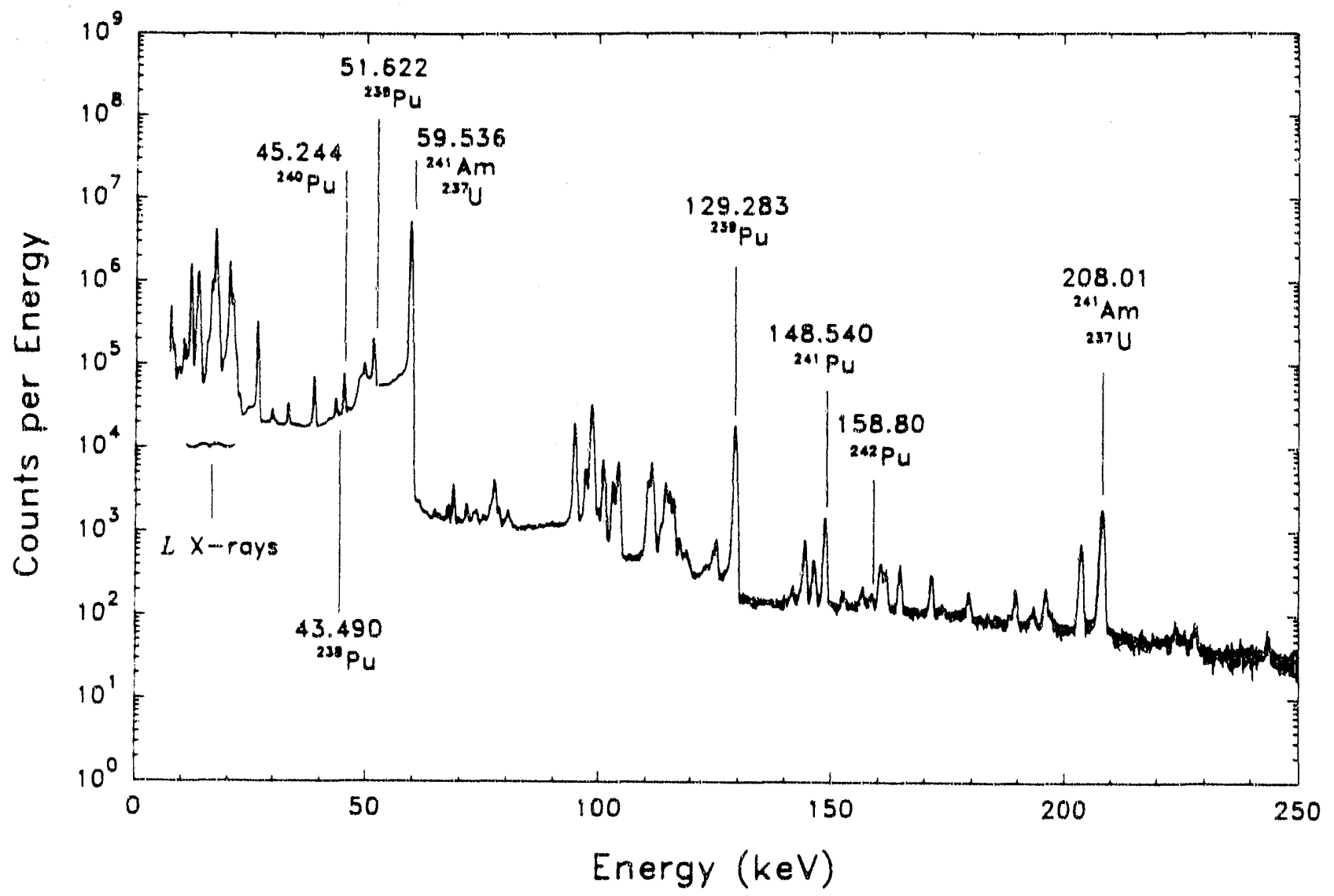

Figure 1. Gamma spectrum of a plutonium sample: The $L \mathrm{X}$-ray region lies between 11 and $23 \mathrm{keV}$; the photo peaks at $59.536 \mathrm{keV}$ and $208.01 \mathrm{keV}$ are characteristic for ${ }^{237} \mathrm{U}$ and ${ }^{241} \mathrm{Am}$.

Table 2.

Isotopic composition and overall uranium $L \mathrm{X}$-ray yields for the plutonium used in the experiments.

\begin{tabular}{ccc}
\hline Pu lsotope & $\begin{array}{c}\text { Composicion } \\
\text { (atom \%) }\end{array}$ & $\begin{array}{c}U L \text { X-ray intensity } \\
\text { yield (\%) }\end{array}$ \\
\hline 238 & $0.012 \pm 0.002$ & $37.7 \pm 2.3$ \\
239 & $93.85 \pm 0.02$ & $39.2 \pm 1.3$ \\
240 & $5.89 \pm 0.02$ & $23.1 \pm 1.6$ \\
241 & $0.220 \pm 0.005$ & $<10^{-3}$ \\
242 & $0.027 \pm 0.002$ & $0.002 \pm 0.002$ \\
\hline
\end{tabular}


Table 3.

Plutonium decay chains. ${ }^{3}$

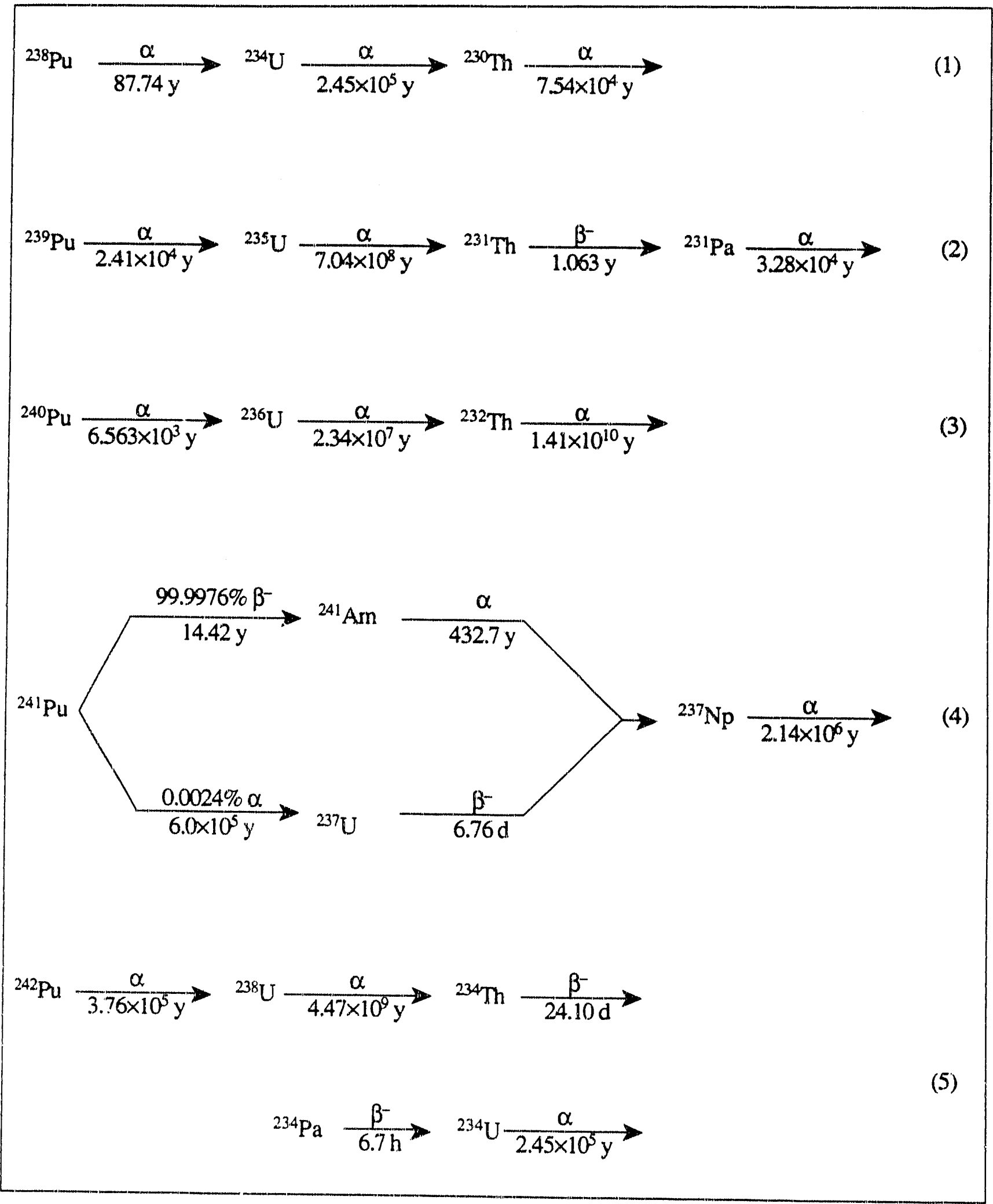


Further decay of ${ }^{241} \mathrm{Am}$ and ${ }^{237} \mathrm{U}$ to ${ }^{237} \mathrm{~Np}$ produces $\mathrm{Np} L \mathrm{X}$-rays, which do, however, interfere with the plutonium assay. This is demonstrated in Figure 2, which compares the $L X$-ray spectrum of a typical plutoniurn sample with the spectra of pure $U L X$-rays and of pure $\mathrm{Np} L \mathrm{X}$-rays. The amount of $\mathrm{Np} L \mathrm{X}$-rays in a plutonium sample is dependent on ${ }^{237} \mathrm{U}$ and ${ }^{241} \mathrm{Am}$. In addition to the $\mathrm{Np} L \mathrm{X}$ rays, both nuclides have photo peaks at $59.54 \mathrm{keV}$ and $208.01 \mathrm{keV}$. The intensities for these energies and for the $\mathrm{Np} L \mathrm{X}$-rays are shown in Table 4. Spectra of pure ${ }^{237} \mathrm{U}$ and of pure ${ }^{241} \mathrm{Am}$ are shown in Figure 3. From these pure standards, we determined the experimental ratios between the $\mathrm{Np} L \mathrm{X}$-rays and the $59.54 \mathrm{keV}$ photo peak. They are 0.81 and 0.50 for ${ }^{237} \mathrm{U}$ and ${ }^{241} \mathrm{Am}$, respectively.

Figure 4 shows how the $\operatorname{Np} L X$-ray correction factor is determined from the $59.54 \mathrm{keV} / 208.01$ $\mathrm{keV}$ peak ratio. For our germanium counting system, we determined this ratio as 6.1 for pure ${ }^{237} \mathrm{U}$

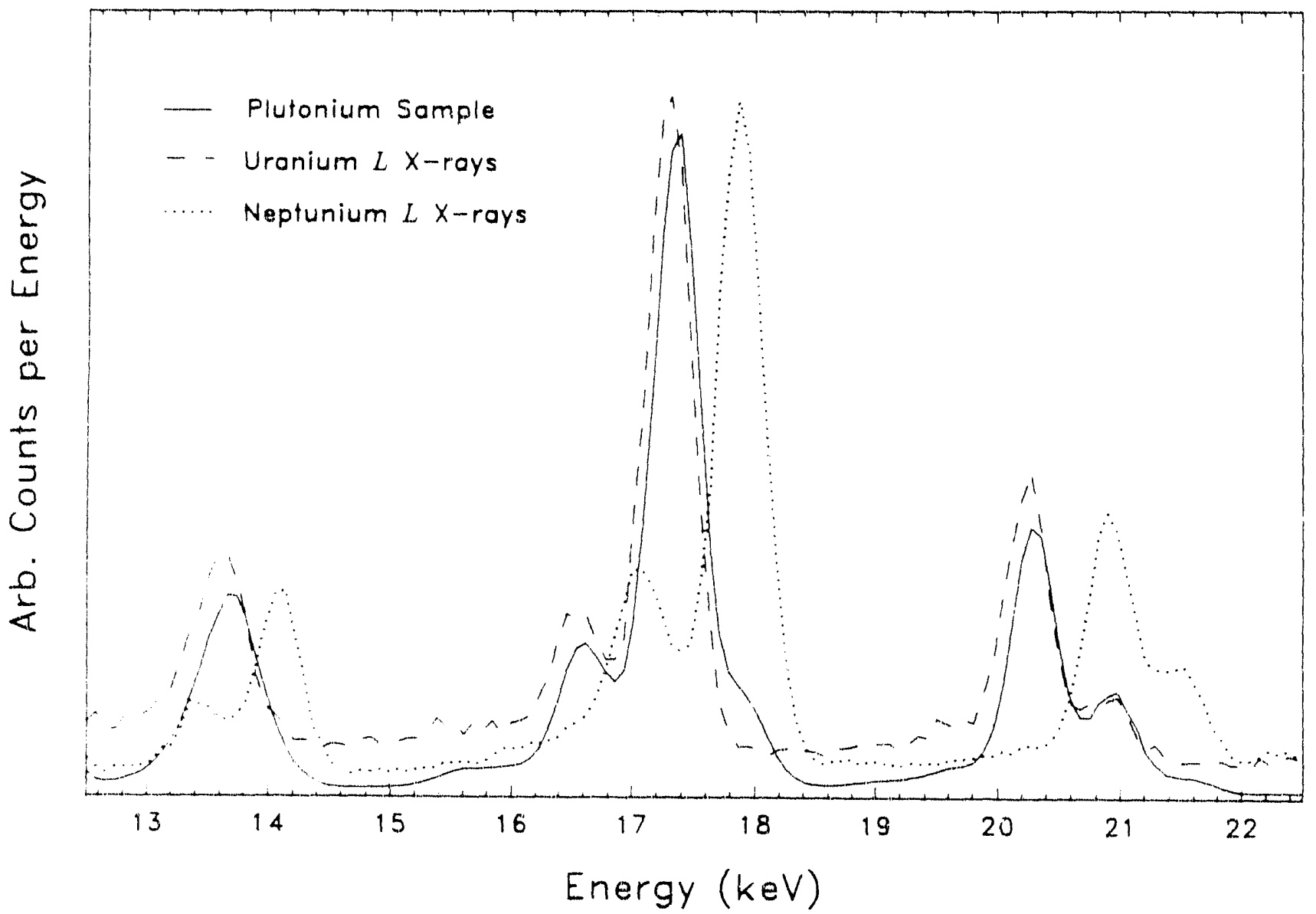

Figure 2. Comparison of the $L X$-ray spectrum of a plutonium sample (solid line) with those of pure $\mathrm{U} L \mathrm{X}$-rays (dashed line) and of pure $\mathrm{Np} L \mathrm{X}$-rays (dotted line): The sample spectrum contains both $U$ and $\mathrm{Np}$ L. X-rays. 
Table 4.

Photon and $L \mathrm{X}$-ray intensities for the decays of ${ }^{237} \mathrm{U}$ and ${ }^{241} \mathrm{Am}$.

\begin{tabular}{lcc} 
& ${ }^{237} \mathrm{U}(\%)$ & ${ }^{241} \mathrm{Am}(\%)$ \\
\hline $208.01 \mathrm{keV}$ & 22 & 0.00079 \\
$59.54 \mathrm{keV}$ & 32.8 & 35.7 \\
$\mathrm{~Np} L \mathrm{X}$-rays & 64.2 & 39.5 \\
$\begin{array}{l}\text { ratio } 59.54 / 208.05 \\
\text { (theoretical) }\end{array}$ & 1.49 & 45,190 \\
$\begin{array}{l}\text { ratio } 59.54 / 208.01 \\
\text { (experimental) }\end{array}$ & $6.1 \pm 0.2$ & $184,000 \pm 32,000$ \\
$\begin{array}{l}\text { ratio } \mathrm{Np} L \mathrm{X} / 59.54 \\
\text { (theoretical) }\end{array}$ & 1.96 & 1.11 \\
$\begin{array}{l}\text { ratio } \mathrm{Np} L \mathrm{X} / 59.54 \\
\text { (experimental) }\end{array}$ & $0.81 \pm 0.05$ & $0.5017 \pm 0.0002$ \\
\hline
\end{tabular}

and 184,000 for pure ${ }^{241} \mathrm{Am}$. We calculated the correction factor of an unknown mixture by linear interpolation of the measured 59.54/208.01 peak ratio. It is important that these corrections be carried out for both the sample and the standard.

\section{Other interferences}

Interferences of the $L X$-ray spectrum can come from radioactive contaminants that are unrelated to the plutonium sample and also possibly from the decay of genetically related nuclides of the plutonium decay chain. This is especially important when solutions with higher concentrations or

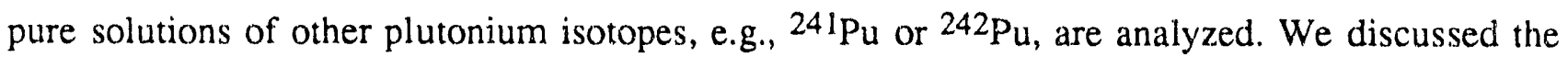
$\mathrm{Np} L \mathrm{X}$-ray correction for ${ }^{241} \mathrm{Pu}$ in the previous paragraph. For ${ }^{242} \mathrm{Pu}$, the $\mathrm{U} L \mathrm{X}$-rays can be contaminated with Th and $\mathrm{Pa} L \mathrm{X}$-rays coming frorn the ${ }^{238} \mathrm{U}$ and ${ }^{234} \mathrm{Th}$ decay, respectively. Appropriate correction factors will have to be determined from pure $238 \mathrm{U}$ solution to correct for these effects on the basis of the ratio of a particular photo peak $\left({ }^{234} \mathrm{Th}, 63.29 \mathrm{keV}, 3.8 \%\right.$ intensity) to the sum of the non-U L X-ray peaks. 


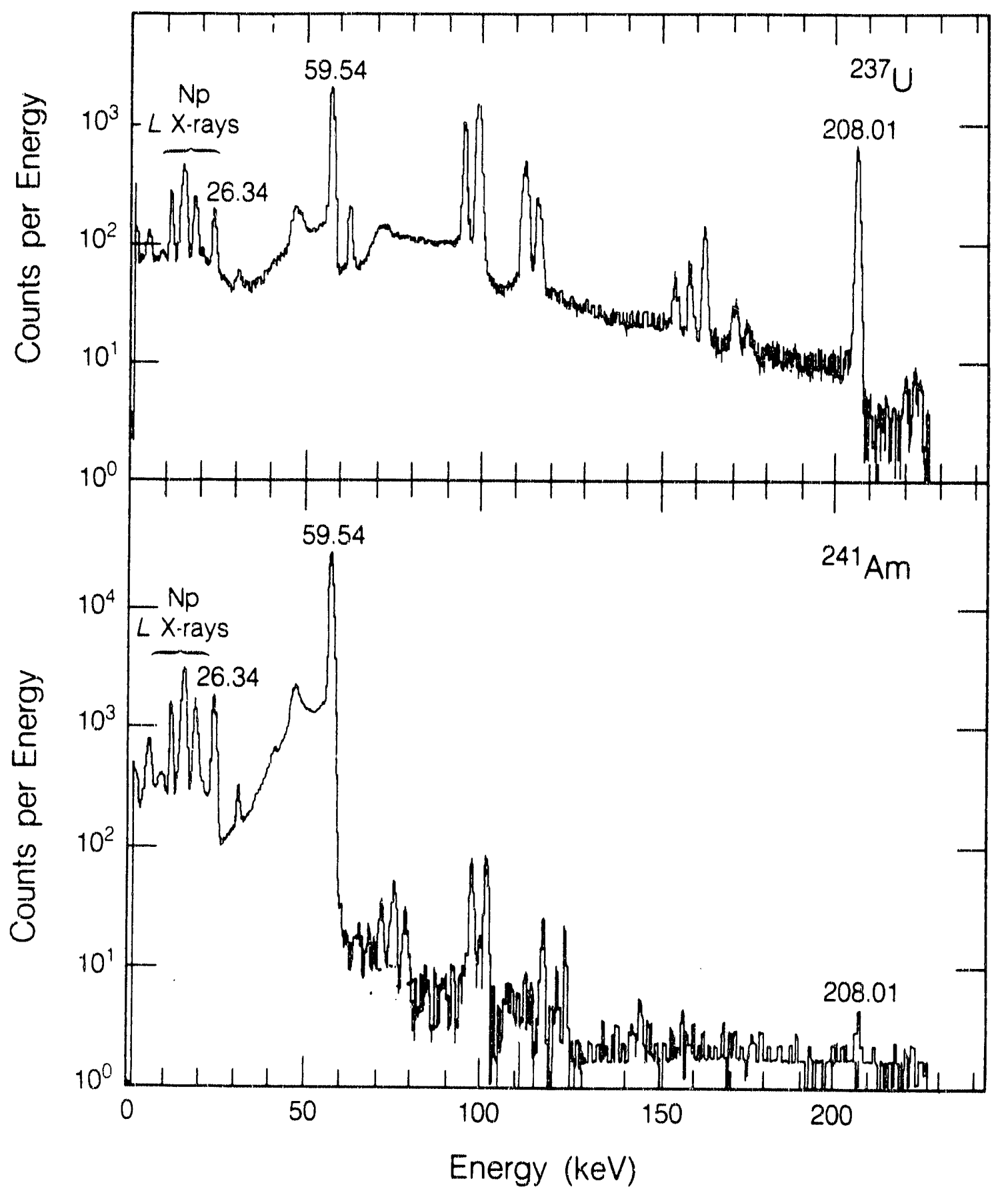

Figure 3. Gamma spectra of pure ${ }^{237} \mathrm{U}$ (upper) and of pure ${ }^{241} \mathrm{Am}$ (lower): The $59.54 \mathrm{keV} / 208.01 \mathrm{keV}$ photo peak ratio is very different. 


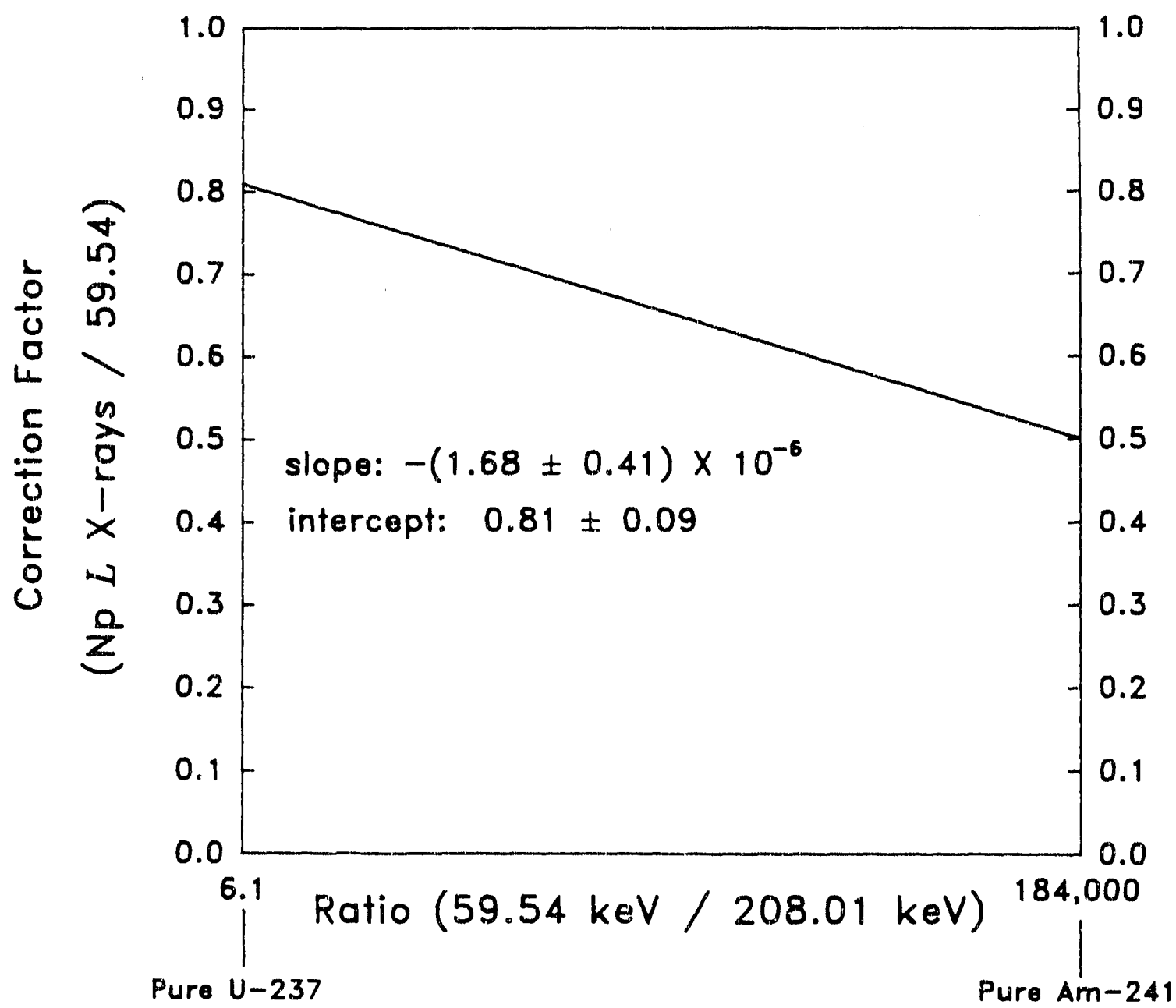

Figure 4. Linear relationship for the determination of the $\mathrm{Np} L \mathrm{X}$-ray correction factor.

\section{EXPERIMENTAL PROCEDURE}

\section{Radionuclides}

The isotopic composition of the plutonium used is shown in Table 2. Isotopically pure solutions of $237 \mathrm{U}$ and $241 \mathrm{Am}$ were obtained by separating these nuclides by means of anion exchange from a ${ }^{239} \mathrm{Pu}$ solution that contained the materials as impurities. ${ }^{4}$

\section{Counting system}

The counter (LBL design) consists of a planar intrinsic germanium detector that measures $36 \mathrm{~mm}$ in diameter and $10 \mathrm{~mm}$ in thickness and has a $0.26 \mathrm{~mm}$ beryllium window. The unit is cooled by liquid nitrogen. The detector is coupled to a preamplifier (LBL design) and an amplifier (Tennelec, Model TC 244) and to a PC-controlled multichannel analyzer (Nucleus, Model PCA 4000). 


\section{Calibration}

We used the sum of all counts in the $L \mathrm{X}$-ray region between about $12.5 \mathrm{keV}$ and $22.5 \mathrm{keV}$ for determining detector efficiency, sample geometry, and the sample attenuation with a plutonium standard. The standard had the same isotopic composition as the samples. Standard and samples were contained in $25 \mathrm{~mL}$ polyethylene vials filled with $10 \mathrm{~mL}$ aqueous solution containing about $1 \mathrm{M}$ $\mathrm{HCl}$.

\section{Accuracy and limit of detection}

Because only a limited amount of solution from the plutonium solubility experiment was available and many samples were required to determine the solubility equilibrium, only $1 \mathrm{~mL}$ was available for each assay. This required relatively long counting times. Table 5 lists the required counting times as a function of molarity and accuracy. The accuracies are $2 \sigma$ values that include the accuracies of the calibration standard, the dilutions, and the counting. A significant decrease in counting time can be achieved by increasing the actual sample volume from $1 \mathrm{~mL}$ to $25 \mathrm{~mL}$. The lower limit of detection was $4 \therefore 10^{-11} \mathrm{M}$ plutonium $(9.6 \mathrm{ng} / \mathrm{L})$.

\section{RESULT}

Figure 5 shows a typical assay from a plutonium solubility experiment with $9.5 \times 10^{-7} \mathrm{M}$ plutonium. The upper spectrum was taken immediately after sampling and the lower spectrum 75 days later. The 59.54/208.01 peak ratio changed with time from 6.1 to 100 . Using the interpolation shown in Figure 4, we calculated identical correction factors of 0.61 . This shows that the solution contained mostly ${ }^{237} \mathrm{U}$ and not ${ }^{241} \mathrm{Am}$. Without this method of determining the correction factor, one could conclude from the presence of the $59.54 \mathrm{keV}$ photo peak that the $\mathrm{Np} L \mathrm{X}$-rays coming from the ${ }^{241} \mathrm{Am}$ decay are contaminating the $\mathrm{U} L \mathrm{X}$-rays. A correction factor of 0.50 for ${ }^{241} \mathrm{Am}$ instead of 0.81 for ${ }^{237} \mathrm{U}$ would have given erroneously high solution concentrations.

Furthermore, we have shown that $U L X$-ray spectroscopy for ths determination of plutonium is a viable alternative to labor-intensive $\alpha$ spectroscopy and elaborate neutron activation analysis.

$U L X$-ray spectroscopy is also applicable for routine assays of plutonium in liquid wastes with unknown isotopic composition. The isotopic abundance can be determined from the low energy 
Table 5.

Sample counting times as a function of molarity and accuracy,

\begin{tabular}{c|c|c}
\hline \multirow{2}{*}{$\begin{array}{c}\text { Plutonium } \\
\text { concentration (M) }\end{array}$} & \multicolumn{2}{|c|}{ Counting time for 1mL sample } \\
\hline $10^{-4}$ & $0.3 \mathrm{~min}$ & $30 \%$ accuracy \\
\hline $10^{-5}$ & $3.6 \mathrm{~min}$ & - \\
$10^{-6}$ & $37 \mathrm{~min}$ & - \\
$10^{-7}$ & $6 \mathrm{~h}$ & $1 \mathrm{~min}$ \\
$10^{-8}$ & $2.5 \mathrm{~d}$ & $11 \mathrm{~min}$ \\
$10^{-9}$ & $25 \mathrm{~d}$ & $1.8 \mathrm{~h}$ \\
$10^{-10}$ & - & $18 \mathrm{~h}$ \\
\hline
\end{tabular}

* The times are for a $1 \mathrm{~mL}$ sample. Larger sample volumes decrease the counting times significantly. The accuracies are $2 \mathrm{~s}$ values that include the accuracies of the calibration standard, the dilutions, and the counting.

gamma rays of the different plutonium isotopes. The specific photo peaks with the least interference from other peaks are marked in the spectrum shown in Figure 1. However, samples with relatively high plutonium concentrations are required for this measurement because these photo peaks have rather small abundance. However, this can be overcome by a simple evaporation concentration step.

\section{ACKNOWLEDGEMENT}

This work was supported by the Yucca Mountain Site Characterization Projec: Office (YMP) as part of the U.S. Civilian Radioactive Waste Management Project through the Los Alamos National Laboratory. The Yucca Mountain Site Characterization Project (YMP) is managed by the U.S. Department of Energy, Yucca Mountain Project. This work was performed at the Lawrence Berkeley Laboratory, which is operated by the University of California for the U.S. Department of Energy undei Contract DE-AC03-76SF00098. 


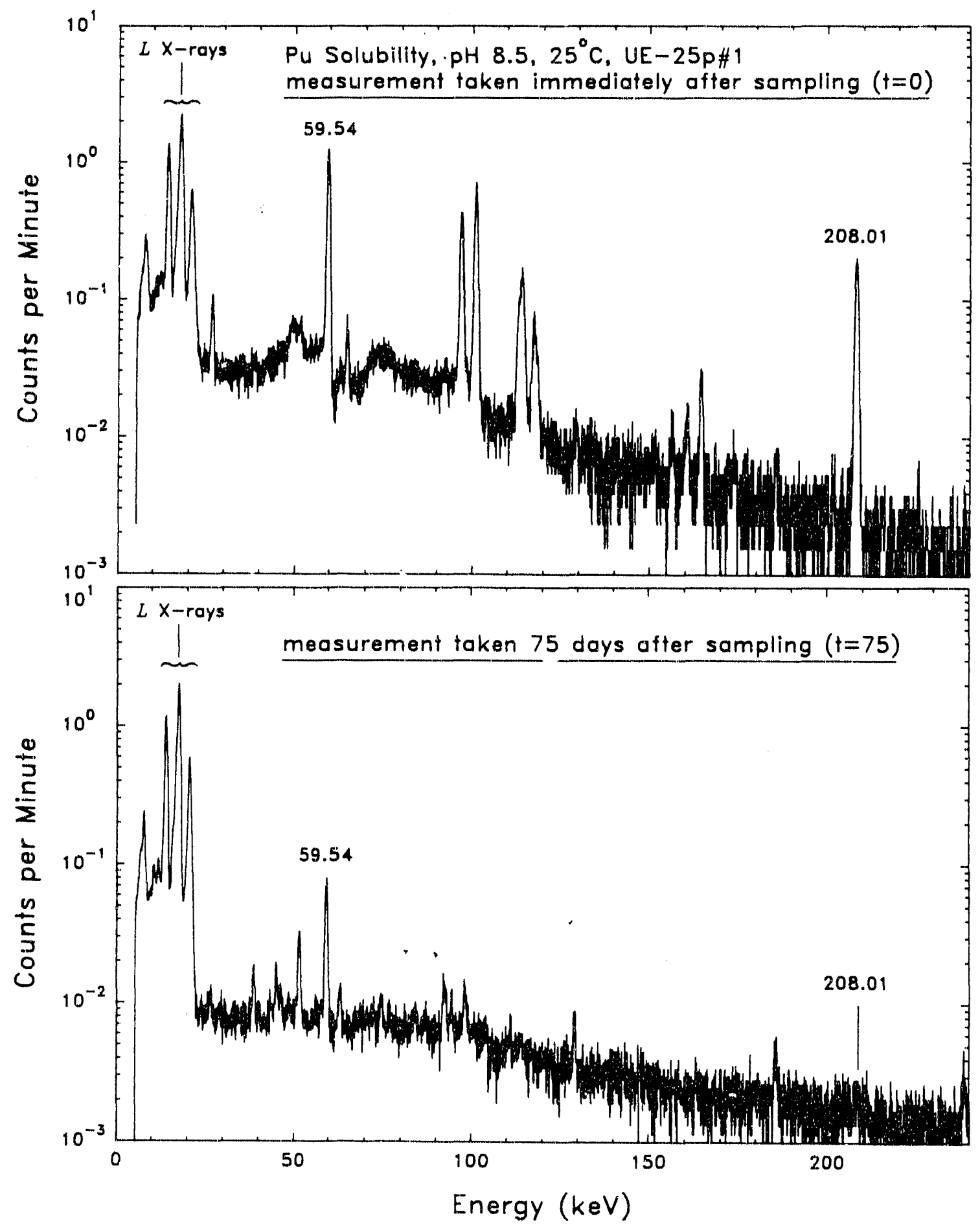

Figure 5. A spectrum for a typical assay with $9.5 \times 10^{-7} \mathrm{M}$ plutonium: The upper spectrum was taken after sampling; the lower spectrum, 75 days later. 


\section{REFERENCES}

1. H. Nitsche, Radiochim. Acta, $52 / 53$ (1991) 3.

2. H. Nitsche, Mat. Res. Soc. Proc., Vol. 212, Scientific Basis for Nuclear Waste Management, T. A. Abrajano, Jr., and L. H. Johnson, eds., Mat. Res. Soc., Pittsburgh, Pennsylvania, 1991, p. 517.

3. E. Browne, R. B. Firestone, Table of Radioactive Isotopes, John Wiley \& Sons, 1986.

4. G. H. Coleman, The Radiochemistry of Plutonium, NAS - NS 3058, National Academy of Sciences, National Reasearch Council, 1965, p.92 - 93.

\section{APPENDIX}

The data used to write this paper are recorded in the following YMP Laboratory Record Books:

TWS-LBL-10-85-01, pp. 29-37, 43-69

TWS-LBL-01-86-09, pp. 3--304

TWS-LBL-06-86-01, pp. 193-205, 259-264

TWS-LBL-05-88-02, pp. 121-129, 161-167, 183-187

TWS-LBL-01-89-02, pp. 43, 93-106, 119-129, 130-131, 229-292

TWS-LBL,-04-90-07, pp. $37-40$ 

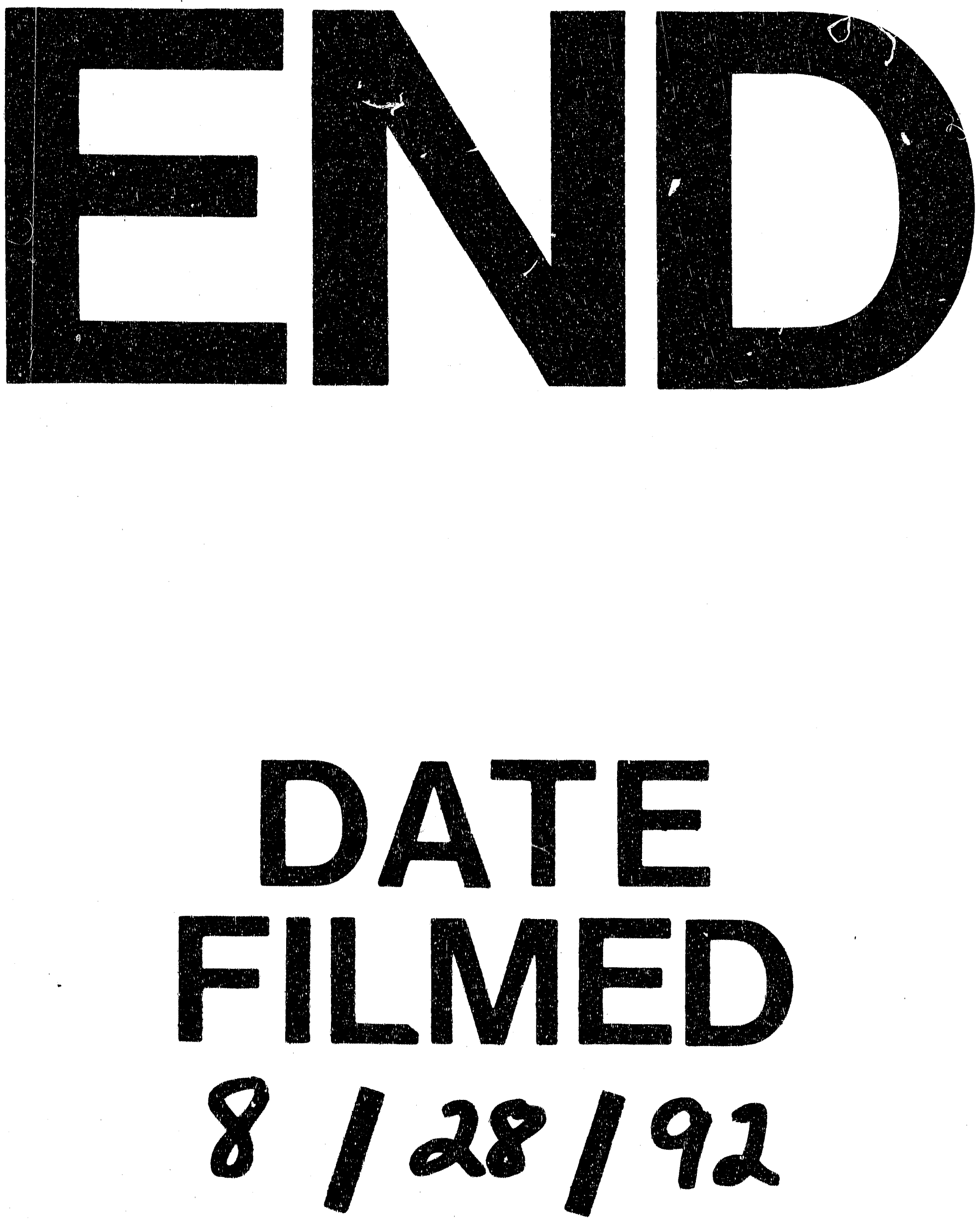
- 